\title{
The application of causal layered analysis to understand the present conditions and possible futures of media and politics in Iran
}

\author{
Sara Talebian ${ }^{1 *}$ and Hamed Talebian ${ }^{2}$
}

\begin{abstract}
The relationship between media and politics in Iran is significantly complicated and multidimensional. Although the so-called independent press and news media are being published in a regular basis, the entire media sphere is being shaped by the state regime, and most of media platforms reflect the state's will. The main goals of this article are to explain the present conditions and characteristics of the relationship between media and politics and to explore the social and cultural causes, discourses, and myths which have allegedly justified the strong governmental interventions and influences in the Iranian media sphere. We consider causal layered analysis (CLA), as a critical futures studies method, to be an appropriate method to deconstruct the present status and envision the future of the relationship between media and politics in Iran. We utilize four different layers of analysis. First, we determine different aspects of litany level, including the role of media in promoting enmity in discourse about Iran's enemies, real and fictitious. Second, we specify different systemic causes for the current relationship between media and politics, including the continuous attempts of Iran's state regime to control and dominate the entire media sphere. Third, we review the two main discourses involved in the 1978-1979 Revolution in Iran. Each discourse is focused on constructing alternative responses to the controversy between tradition and modernity in the contemporary history of Iran. Fourth, in the entitled level of metaphor or myth, we identify the narrative of "Educating the Populace" as the deepest myth behind the relationship between media and politics in Iran. At the next stage of this study, we construct the possible scenarios for the future of the relationship between media and politics in Iran based on the dominance of competitive root discourses. Finally, we argue that one should go beyond the discursive layer to find the alternative futures of the relationship between media and politics in Iran. These alternative futures are associated with the emancipation from the competition between the traditionalism and modernism discourses and changing the deepest myths behind the relationship between media and politics.
\end{abstract}

Keywords: Causal layered analysis (CLA), Futures studies, Futures methods, Media and politics in Iran

\section{Introduction}

Media and politics are tightly interconnected in Iran; thus, political deployment and a predilection for different political opinions and objectives are crucial aspects of Iran's media sphere. As diverse, independent, and dissident political parties and interest groups are apparently not involved in the political system in Iran, almost all media platforms represent the political interests and

\footnotetext{
* Correspondence: sara.talebian@helsinki.fi

${ }^{1}$ Helsinki University, Helsinki, Finland

Full list of author information is available at the end of the article
}

objectives of the state regime, though these objectives might be proposed by different power sects or various political structures. They also play a focal role in the political determination. Even though the left-right political conflicts and negotiations have created a rich diverse political sphere in Iran's contemporary era, the common trait here is the absence of ordinary people and public participation in the political processes. Instead of establishing an institutional process for involvement in the media sphere, politicians on both sides fully expect media to inject their desired political objectives into the 
collective subconscious. Nevertheless, informal politics influence decision-making behind closed doors, particularly upon the advent of alternative media. While the official and mainstream media platforms are being controlled by the state regime, alternative interest groups use alternative media and communication platforms to raise their pluralistic demands, though these alternative platforms are usually under several major limitations; for example, they may be banned or filtered.

Politicians have always attempted to control and dominate media power using top-down tactics to varying extents. Whether during the Pahlavi era or after the Iranian Revolution in 1978-1979, the history of media and communication in Iran indicates that all the state regimes and governments have aimed to control the media sphere by different means, like through censorship or licensing [1]. Media platforms are not officially governmental organizations, and they are not included in the state's structure; thus, hierarchical orders in the political structure cannot be applied to media platforms. Consequently, officials and politicians resort to employing different media platforms to advocate their political interests. These interests may be advanced through official apparatus, like enforcing a law or legalizing censorship, or unofficial ones like threatening and bribing journalists or fulminating against those who do not support a certain political opinion or objective. Overall, the most significant issue in the relationship between media and politics in Iran is the fact that media have always been controlled and dominated by the politics and political structures. After the establishment of a modern centralized state regime in the country, all the political systems and governments in Iran have tended not to cooperate, negotiate, or participate but to control, bridle, and supervise the media.

Despite all the attempts to control the media sphere, the alternative media have been the essential tools to raise public demands and give voice to the voiceless in Iran's history. Although the official and mainstream media have always been under the control of the state regime, alternative media have succeeded in affecting official politics in different dimensions. They have influenced several political outcomes and decision-making processes, not only after the advent of social media but also during the broadcasting era when the underground press played an unprecedented role in the Persian constitutional movement, which was mainly against the divine right of the king to rule the country and set the politics [2]. Alternative media resonate with new social and political demands such as reform, freedom, equality, social democracy, and citizenship, which are issues that remain focal points of various contemporary social struggles against traditionalism in Iran. In the recent years, the Internet developments and the emergence of new media platforms provide more feasible and diverse tools and channels to echo alternative voices and demand for public participation in the political procedures and decision-making. In this context, it seems that the technology has created a new opportunity for ordinary people, as well as critical intellectuals, to play a more influential role in the political decision-making processes. Although these alternative voices and informal politics have been significantly reflected through alternative media, a relatively free media sphere has not emerged in Iran, as the majority of media platforms are still controlled by the state regime, and the necessary alternative political structures and institutions like political parties are absent in the political system.

To sum up the current relationship between media and politics in Iran in one glance, the mainstream media are dominated by the state regime and aim at promoting and propagating the state regime's political interests and objectives. At the same time, the alternative media try to resist top-down politics to pursue the growing demands of plural social strata in Iran.

To understand the pseudo-contradictory status of Iran's media sphere, we need to strip away the outward layers in which the alternative media, backed by revisionist political objectives, resist mainstream media which are striving to institutionalize official governmental politics. The duality between mainstream and alternative just demonstrates a few narrow aspects of the entire reality of which all media practice as well as political priorities have the same trait and modality, particularly in a longer time frame. Causal layered analysis (CLA) is one of the most credible theoretical and methodological frameworks to understand the deeper social causes and worldviews behind this reality. Following a critical approach, our commitment to futures studies is retrieved from the deconstruction of a limited pretence that the old traditionalist system of political objectives (backed by the Islamic-regime controlled media) could be tackled by the modernist media confrontation. The more we are immersed in the historical data and layers of analysis, the less we are satisfied with the claims that highlight the alternative media sphere as a key driving force for the political transformations. In other words, we aim to show that the deepest narrative behind both the traditionalism and modernism discourses in Iran is the same narrative emphasizing educating the populace.

Our final objective in this text is to discover an alternative beyond the so-called discursive struggles between tradition and modernity. In addition, to investigate the external layers of analysis indicating how the contradiction between opposite media agendas backed by different political objectives are formulated, we elucidate the deepest layers of metaphorical analysis indicating the remarkable similarity and compromise on principles and practices of the traditionalism and modernism 
discourses in Iran's media politics. We argue that educating people, instead of informing them, is the most preventive myth in the deepest layer of the relationship between media and politics. After constructing the possible futures scenarios based on the discourse layer, we also explain a vision of an alternative critical future which can be imagined transforming the situation from the status quo into a more desirable scenario. This part is the most important contribution of this paper to the literature of media politics. We claim that this alternative vision has a great credibility to open a spectrum of alternative futures for the relationship between media and politics.

\section{Why CLA?}

Causal layered analysis (CLA) is known as a critical futures research method which deepens the understandings about the futures changes. According to Inayatullah, CLA is based on the assumption that the way in which a problem is framed will have an impact on how a change in the issue will be pursued [3]. While the theoretical underpinning of CLA is based on post-structuralism, the approach is layered, that is, it is a method of analysis which is inclusive of accounting for various streams of causality operating in unison upon an issue [4].

As Inayatullah [3] explains, causal layered analysis (CLA) consists of four dimensions. The first is the litany, or the day-to-day layer, the commonly accepted headlines about the way things are or should be. Solutions to problems are, at this level, usually short term. The second dimension is deeper, focused on the social, economic, and political causes of the issue. The third dimension is the culture or worldview. This is the big picture, the paradigm that informs what we think is real or not real, the cognitive lens we use to understand and shape the world. The fourth dimension is the myth or the metaphor-this is the deep unconscious story behind the issue.

CLA seeks to integrate these four levels of understanding. Each level is true, and solutions need to be found at each level. Litany interventions lead to short-term solutions, easy to grasp, and packed with data, while social and economic interventions are linked to deeper and more systemic solutions which are usually constructed through governmental policies. Worldview change is much harder and longer-term. It requires seeking solutions from outside the framework in which the solution has been defined. And the myth solutions require the deepest interventions, as this framework requires telling a new story, rewiring the brain, and building new memories and the personal and collective body [5].

CLA has been vastly utilized in many different studies in the previous literature. Different studies have used CLA as the main research framework or as a participatory environment for conducting workshops. It has been applied in various case studies as a stand-alone method or in combination with other futures methods like scenarios, futures wheels, and backcasting. Some of the most important practices of CLA are packed and presented in the book, "The Causal Layered Analysis (CLA) Reader." According to Inayatullah [3], Bangkok traffic futures (1993), the future of enrolments (1994), housing persons with disabilities (1995), and the future of United Nations (1996) are some of case studies applying CLA in research frameworks and the workshop environment. In some recent studies, Lederwasch et al. [6] apply CLA to create the future visions of mining and mineral industry in Australia; Shevellar [7] reflects upon the usefulness of CLA as a means of responding to dilemmas within the current practice of community development; and Bishop and Dzidik [8] utilize CLA as a qualitative methodology well-suited for psychology and define a space for its adoption in the discipline.

CLA aims to dig deeply into how the thinking of those participating in futures works directs them in foreseeing the future [9]. The benefits of CLA include bringing scope and richness to scenario thinking, helping with taking into consideration the different knowledge-related practices and abilities of the actors, connecting the less "hard" sciences to the future processes, and moving the discussion naturally from a self-evident level to deeper levels. In this sense, we find CLA an appropriate method to analyze the relationship between media and politics in the present and the future in a deepened manner and to explore the role of key actors and influential parties in this relationship.

Moreover, CLA assists us to view the relationship between media and politics in Iran in a historical and deepened manner and to analyze this relationship in different layers. Accordingly, this study identifies and analyzes social causes and crucial actors of media and politics in Iran and explores which cultural worldviews and unconscious narratives have justified the present situation. Moreover, by applying CLA and recognizing the central worldview behind the relationship between media and politics, the possible scenarios for the future of media and politics in Iran are constructed in a discursive and critical manner.

According to the CLA approach, every phenomenon is constructed in at least four diverse levels, which contain their specific time horizons, analytical realms, causal conjunctions, and practical solutions. Thus, critical futures studies, and CLA as a critical futures research method, are not only about anticipating and constructing the futures scenarios. As Inayatullah [10] explains, in critical approach, the task is not one of predictions or comparisons (as in the interpretive) but of making units of analysis problematic. In other 
words, the critical approach aims to deconstruct the present power relations, understand the historical causes and discourses which resulted in the present situation, and evoke alternative possibilities for the future.

This study reflects upon the crucial usefulness of CLA in studying the relationship between media and politics in general by focusing on the analysis of this relationship in the case of Iran. Exploring this relationship in Iran as a case study is not only crucial for anticipating the future challenges in Iran in a bigger picture but also a good theoretical and methodological approach to analyze the relationship between media and politics in other countries and other contexts. Any political entity, whether it is a nation-state or a larger one like the European Union, must establish a particular articulation between media obligations and political objectives, and CLA can be an appropriate method for such an articulation.

In this sense, the application of CLA for critical analysis of the relationship between media and politics in Iran is significantly useful and important from a European perspective due to the fact that it not only provides an appropriate case study, the method of which academicians can pursue, but also might facilitate the deconstruction of the relationship between media and politics in other contexts like the European countries. With a deconstructive perspective, knowledge is achievable and conceivable by the contradictory negations, instead of the affirmative harmony of descriptions. Thus, our findings might indirectly provide an outlook for the media politics in Europe by demonstration of how distinct relationships between media and politics are established in Iran, currently or throughout history.

In this paper, we unfold the most vital story, which has been told by Iranian intellectuals and politicians throughout the modern history of Iran to legitimate a particular set of power relations between media and politics. This story introduces media as the means for educating people, and it differs significantly from the conventional Western narrative that articulates media as the vital instrument to promote and protect the freedom of speech on the one hand and recognizes politics as the crystallization of public demands expressed through mediated channels on the other hand. We explain and explore the implications of this deep story for the relationship between media and politics in Iran in different layers, while we advocate the Western model of media politics as an alternative and more desirable alternative for Iran. However, the plausibility of such an alternative and the role of Western influential parties, like academies and media platforms in shaping an alternative relationship between media and politics in Iran, remain the unexplored questions. Thus, this manuscript might assist the European political powers and media initiatives in understanding the current relationship between media and politics in Iran, including its deepest discourses and narratives, and facilitate the emergence of alternative possibilities in the future, of course without a direct linkage between Iranian issues and European notations.

\section{Litany layer: contemporary media and politics in Iran}

The litany level is the most visible and obvious, requiring few analytic capabilities. It is believed, rarely questioned. As Inayatullah says, the litany level is about the superficial and present problems, issues, events, and trends [3]. They are usually presented in news media, routine documents and reports, and current rules and legislation. Regarding the relationship between media and politics in Iran, at the litany level, all the relevant news, documents, and laws on the interconnections between politics and media sphere are of concern. In this sense, we scan many different documents, particularly all the relevant reinforced laws and legislation on media and media regulations in Iran. By scanning, collecting, and conducting exploratory content analysis, we identify the crucial key elements with which the present relationship between media and politics in Iran is shaped and defined (Table 1).

Table 1 Key elements of the relationship between media and politics in the litany layer

\begin{tabular}{lll}
\hline Key elements & Mainstream & Alternative \\
\hline Media ownership & State monopoly in broadcasting & Private and commercial ownership in press media \\
& State-owned press & Foreign ownership in digital and social media \\
& State-owned media infrastructure & \\
Media control & Licensing and license detention & \\
& Filtering & VPNs, anti-filters, and other internet proxies \\
& Parasites & Satellite television channels \\
& Restrictions on broadband infrastructures & Underground publications \\
Media content production & Traditionalist & \\
& Islamist & Secular \\
& Anti-Western & Modernist \\
& & Pro-Western \\
& & Semi-nationalist \\
\hline
\end{tabular}


Media ownership is the first key element of the relationship between media and politics in Iran. Following a conventional categorization of media, all media platforms can be assigned one of three categories including press media, broadcast media, and digital media. The majority of the mainstream media in all three categories are owned by the state regime in Iran. State-owned media can be defined as media which are financially and editorially controlled and administered by different governing bodies and departments. ${ }^{1}$ Regarding this definition, radio and television broadcasting in Iran is completely owned and monopolized by the state regime, while digital media and press media are partly state-owned, while some kinds of privately owned and alternative media are coexisting with the state-owned ones as well.

Article 175 of Iran's constitution [11], which guarantees the freedom of expression in radio and television broadcasting, of course in keeping with the Islamic criteria, explains that, "the appointment and dismissal of the head of the Radio and Television of the Islamic Republic of Iran rests with the Leader." Moreover, Article 175 states that a council consisting of two representatives each of the President, the head of the judiciary branch, and the Islamic Consultative Assembly, the Iranian Parliament shall supervise the functioning of IRIB [11]. The first article of the statute of IRIB [12] emphasizes the state regime's ownership and administration and determines that radio and television broadcasting (IRIB) is administered based on the said law, the law stipulating the policies of the organization and this article of association under the joint supervision of the three branches of government.

According to the regulations related to the Internet infrastructure, the access service provider (ASP) for Internet connections is monopolized and owned by the state regime. Every governmental department or public sector which demands to provide its own ISP must request a legal license and official permission from the Ministry of Communication [13]. Although the Internet in Iran is under the strict control of the state regime and the control is being reinforced through different surveillance and filtering policies [14], there is a counterflow of unofficial and alternative media platforms that many Iranian users have access to with the help of VPNs and anti-filters. For instance, there are many different blogs and web pages that are filtered by the force of government, but they are still producing different kinds of digital contents for their target audiences (e.g., private and personal blogs, podcasts, pages and groups on social media).

According to Iran's press law, the publication of private and commercial press is allowed for any actual or legal person with specific criteria, like having Iranian citizenship, having the financial resources, and proving particular literacy qualifications [15]. In this sense, press media platforms are relatively colorful in Iran, and many different private presses are being published in different fields. However, there are several print and online press media that are owned and administered by the state regime. These presses are considered public media in some official documents and regulations, but they meet the characteristics of state media in several significant ways. They have an annual share of the annual government budget, they use state-secured funds, and they are under the control of the state regime financially and editorially. These press media are usually considered as the mainstream print media in Iran since they have bigger circulations and they do not encounter any financial problems due to their stable share of governmental budgets.

Djankov and his colleagues [16] argue that state-owned media distort and manipulate information to entrench the incumbent politicians, preclude voters and consumers from making informed decisions, and ultimately undermine both democracy and the markets. In contrast, private and independent media supply alternative views to the public and enable individuals to choose among political candidates, goods, and securities-with less fear of abuse by unscrupulous politicians, producers, and promoters. Moreover, the notion of competition among private and commercial media ensures that voters, consumers, and investors obtain, on average, unbiased and accurate information.

Media control is the second element of the relationship between media and politics in Iran. Whether in the Islamic Republic of Iran state regime or in the previous imperial government in Pahlavi era, all different regimes and governments have always aimed to control and suppress the media sphere in Iran by any means. The general methods Iran's state regime employs to control and dominate the entire media sphere are the following: determining broadcasting media policies in a governmental supervision council, press media license detention, visible and invisible ways of censorship, and filtering digital media contents on the Internet.

As Mohsenian Rad [1] notes, in the first years of private radio broadcasting in Iran, the imperial government was exerting many different approaches of censorship to prevent any kind of voice diversity in the radio programs, particularly in news and political contents. After the monopolization of media broadcasting in the Pahlavi era and the continuous state ownership of broadcasting systems after the Iranian Revolution of 1978-1979, the whole process of policy making came under the control of the new regime. Article 16 of the Islamic radio and television broadcasting statute [12] determines the duties and authorities of the supervisory board. According to this article, the supervisory board is authorized to determine, prepare, and modify the general broadcasting policies and 
propose the policy documents to be approved by Iran's Parliament (note 1). In addition, this board has the power to supervise the broadcasting activities to ensure they are in accordance with general policies, and to control the frames of radio and television productions and programs to be consistent with the state's political policies (note 2, note 3 ). The broadcasting supervision council is even authorized to intervene in minor management issues, such as appointment and dismissal of senior and mid-level managers of the broadcasting system in offices both domestic and abroad (note 15). This can illustrate the dominance and authority of the state regime and its branches on the radio and television broadcasting system.

According to Iran's press law [15], any publication, whether in print or in online news media, by actual and legal persons with Iranian capital, requires obtaining a license from the Ministry of Culture and Islamic Guidance. Therefore, every commercial and private press is, in a way, under the control of the state regime. A press supervisory board is established to issue press licenses and investigate the required qualifications of the actual or legal person who seeks the license (article 11). The press supervisory board consists of seven members from different state sectors, taken from the following: the Ministry of Justice, the Parliament, the Supreme Council of Cultural Revolution, Hoze-Elmie-Ghom (the main Shia religious school in Iran), press director (chosen from within), and universities' professors (chosen by the minister of Science, Research, and Technology); the final member is the Minister of Culture and Islamic Guidance. Obviously, all the decisions of the supervisory board are under the control and dominance of the state regime, since it has six members out of seven on the board. In other words, the state regime is entitled to decide who is eligible to have a publication license and who is not.

In addition, the press supervisory board is responsible for investigating and probing the violation of law by any publication and for reporting to the Ministry of Justice. The press court, which is a part of the Ministry of Justice, is authorized to punish any violator by temporary suspension or permanent license detention. Iran's press law [15] determines what kinds of contents and acts are considered violation of law; accordingly, the state regime is actually controlling the process and quality of content production in all private and commercial press and news media as well.

However, it must be mention that there is a counterflow of press and online media in Iran which allows the audiences to use alternative media contents by bypassing the state regime's control. For example, a small number of the underground press are being published in Iran without having any official license or being supervised by the press supervisory board [17]. The satellite television channels which are considered illegal and do not have any broadcasting licenses in Iran are another example of this alternative media flow. Similarly, many Internet users in Iran use VPNs and anti-filters to get access to online websites and digital media platforms that are filtered by Iran's state regime. In this sense, Iranian users are using a considerable number of social networking platforms (i.e., Twitter, Facebook, Instagram, and Telegram) and online news media (i.e., BBC and VOA) though many of these digital media have been banned and filtered by the state regime or operated within the multiple legal limitations.

The influence of the state regime on media content production is the third element of the relationship between media and politics in Iran. Generally, the fundamental goal and mission of the state-owned media platforms in Iran is to recreate and propagate the political and cultural discourses, which are desirable and advantageous for the state regime, particularly Islamic-based ones. Hence, it can be claimed that the state regime in Iran aims to use its own media and enforce private independent media platforms to promote and propagate the Islamic, traditional, and ideological values and discourses.

According to Article 9 of the radio and television broadcasting statute [12], the main goal of radio and television broadcasting is to promote the Islamic culture. The other indicated aims of the IRIB are the following: preparing the social environment for public education and refinement, increasing people's moral virtues, and accelerating the evolutionary path of Islamic Revolution worldwide. The Article 11 of the mentioned statute emphasizes the international function of broadcasting and explains that radio and television broadcasting have to develop international relations and communications in the light of Islam and Islamic standards. Similarly, the third article of the law for general policies and principles of the Islamic radio and television broadcasting [12] obligates all the media broadcasting programs to consider the supreme leader's demands and discernments as the core priority in all aspects of content production. Moreover, several articles of the mentioned law emphasize the responsibility of radio and television broadcasting for preventing the promotion of Western culture and critics of an Islamic Revolution.

In Article 2 of Iran's press law [15], it has been stated that all press media have an essential duty to preserve and consolidate the Iranian state regime's anti-Western cultural policies. All press media are responsible for promoting Islamic cultural values and norms, and they must combat the manifestations of Western and colonialist culture. According to this article, press media must be in line with the Islamic Republic of Iran's policies and paths. In a newer revision, which has been included in Iran's press law [15], all these responsibilities have been applied to all online and digital news media, digital 
versions of press and publications, and online news agencies and websites. In this sense, all different kinds of news media platforms including traditional press and Internet-based online news media are restricted by the state regime to produce media content inside the dominant Islamic discourse. The violation of these rules and norms is considered to be a violation of the law, and the violator media platform will be subject to a vast spectrum of punishments and penalties.

As mentioned before, there has always been a media counterflow that attempts to appear as an alternative platform and bypass the state regime's restrictions. Accordingly, alternative media platforms in Iran, meaning those independent media that can bypass the control and censorship, usually aim to produce some alternative media contents. These alternative media try to provide their audiences with different modernist media content including secular, feminist, environmental, liberal, leftist, and ethnic-based ideas. They empower the audiences to choose their desired content among a colorful spectrum of contents. However, it can be said that these media platforms are generally concentrated on pro-Western and somewhat anti-traditionalist values and cultural characteristics.

\section{Systematic causes: semi-totalitarian regime and its dissidents}

The level of the social cause in CLA is the systematic level in which the social causation in terms of the links between the individuals and society are analyzed. According to Inayatullah [18], the role of the state and other actors and interests is often explored at this level. As he explains, the two key questions asked at this level are, "who is responsible for this?" and "what policies and structures gave rise to this?". Accordingly, we aim to analyze different key actors involved in shaping the relationship between media and politics in Iran. We explain the role of each actor, the historical period in which each actor and its role have been crucial and influential, and the main reasons and causes that made every actor to play a role and act in a certain trajectory.

The state regime has always been the key actor that determined the relationship between media and politics in Iran (Table 2). After the Iranian Revolution and from the first days of the establishment of the Islamic Republic of Iran, the state regime attempted to control and dominate the media sphere locally and nationally. State ownership of the only broadcasting system in Iran; the publication of several state-owned newspapers, press, and online news media; and the use of different tools of suppression like censorship, filtering, and license detention are the manifestations of the state regime's attempt to dominate all kinds of media platforms in Iran. The state regime's dominance over the media sphere is also extended to the telecommunication technologies and infrastructures. For example, almost all the key telecommunication infrastructures for the Internet connections in Iran are state-owned and cross over a state firm, known as the "Telecommunications Infrastructure Company (TIC)" [19]. According to different laws [12, 20], private individuals and organizations are not allowed to import or possess any kind of broadcasting technological infrastructure in Iran. Moreover, the activity of any private and/or foreign radio and television channel accessible by the satellite receivers are forbidden and considered illegal.

As a semi-totalitarian regime, Iran's state regime has always aimed to dominate the media sphere to use it as a propaganda machine that works in favor of its own ideological discourses and against its dissidents. Promoting Islamic and revolutionary values is one of the most crucial objectives of the state regime, and it can be accomplished by dominating and using the media sphere. As mentioned before, promoting and propagating Islamic values has been repeatedly mentioned in different laws, legislation and instructional recommendations as the main ultimate purpose of media in Iran. In addition, Iran's state regime influences the media sphere in demanding propagation of enmity toward Western countries and preventing the extension of Western cultural values. As the idea of Western enmity becomes the focal node after its establishment, state-owned media broadcasting and press have also historically tried to emphasize the Islamic revolutionary discourses [21, 22]. For example, the state-owned broadcasting system in Iran extensively covers the annual demonstrations on the anniversary of the 1978 Revolution, in which the ideological slogans against the United States of America

Table 2 The key actor in the relationship between media and politics

\begin{tabular}{|c|c|}
\hline Actor & - The state regime (key actor) \\
\hline Influential period & - 1978-present \\
\hline Reason & $\begin{array}{l}\text { - Promoting socialist economic values } \\
\text { (and some liberal values and concepts } \\
\text { like entrepreneurship) in recent years } \\
\text { (particularly in the mid-1990s) } \\
\text { - Promoting Islamic and revolutionary } \\
\text { values } \\
\text { - Propagating the idea of enmity between } \\
\text { Iran and Western countries, specifically } \\
\text { the USA } \\
\text { - Mobilizing public masses against } \\
\text { pro-Western elites }\end{array}$ \\
\hline Influence on media politics & $\begin{array}{l}\text { - Dominating media ownership } \\
\text { - Dominating media content production } \\
\text { - Controlling media by censorship/filtering } \\
\text { and other suppression means } \\
\text { - Handling key media infrastructures like } \\
\text { ASPs or broadcasting } \\
\text { - Banning alternative infrastructures like } \\
\text { satellite TV or private ASPs }\end{array}$ \\
\hline
\end{tabular}


are repeated every year. In this sense, the state regime has always utilized the dominated media platforms to not only promote the enmity with Western countries but also to implicitly mobilize the public mass against pro-Western social communities and elites.

However, the state regime is not the only actor in the relationship between media and politics in Iran. In the current historical period, other actors have become influential and effective in determining this relationship by their roles and their original aims [23]. About 10 years after the Islamic Revolution in Iran, when the governmental economy and pro-socialist economic policies started to fail in realizing their promises and privatization of economy started to rise, the market became a crucial actor in the media sphere in Iran. Commercial and private newspapers and publications started to emerge, and they were supposed to convey a counterflow of content production in the media sphere.

In 1997, when the reformist political parties succeeded to win the presidential election, a powerful public demand emerged for a colorful media sphere. As many claim [24-26], the reformist government aimed to relatively decrease the control and pressure on the civil society to allow the private press and media to be more independent and to allow more the freedom of speech. In this era, the civil society in Iran became an important actor in the relationship between media and politics. The civil society was empowered to facilitate the publication of small and medium size newspapers and different kinds of publications. At the same time, the reduction of state control over the media sphere caused the emergence of more independent media platforms striving to convey a voice for the voiceless. Although many relatively independent newspapers emerged in this era, trying to stand in a critical position in contrast with state-owned media, many of these publications encountered license detention and became suspended by the state regime's judiciary which was generally in line with the supreme leader and the previous president of Iran who generally had enough legal capability to dictate macro-policies of regime.

Technology has been another key actor in the relationship between media and politics. From 2005 till the present, the growth of telecommunication technologies, the rise of the Internet and satellite television channels, and the emergence of social media platforms have changed the relationship between media and politics and affected the crucial role of the state regime in determining the rules and regulations of the media sphere. The wide access to, and the huge range of, opposing media content, and comprehensive information on the Internet made the digital and online media relatively uncontrollable by the state regime. Although the state regime strongly attempts to control the digital media by different means of filtering, the emergence of VPNs and other proxies have empowered the Iranian people to use the digital media in the way they want and access almost anything they want on the Internet. Similarly, when the television and radio satellite receivers became accessible and popular in Iran, many media users started to consume these media platforms' production instead of the state-owned broadcasting programs transmitted by IRIB or conventional state-owned press media. Despite the official legislation which bans the consumption of satellite channels in Iran, millions of Iranians watch foreign-based channels via illegal satellite dishes and receivers at their homes and regularly use these satellite television channels [27].

It can be claimed that although the market, civil society, and technology have played crucial roles in determining the relationship between media and politics in Iran, the state regime has been and still is the most important key actor. The only legal broadcasting system in Iran with more than $95 \%$ of Iranian population as its audiences is still owned by the state regime and administered by the state regime. The number of state-owned print and online news media is far larger than the private and relatively independent media, and they are financially secured by the state secure budgets and financial aids. Hence, they are far more influential in the media sphere by having higher circulations. Moreover, the state ownership of the Internet infrastructures in Iran makes the state regime capable of controlling the speed and traffic of the Internet broadband. In this sense, when the state regime has complete control over the ASP and is also capable of tracking digital transactions and controlling the speed and traffic of the Internet, one could conclude that it is extremely difficult for the Internet users to use VPNs and proxies, specifically in crucial situations. For example, in 2009 post-election protests in Iran, the state regime almost shut down the Internet. The speed and traffic of data transformation were extremely low; thus, nobody could even use the regular non-filtered web pages.

\section{The worldview: controversy between traditionalism and modernism}

To grasp the deeper layer of causes, we must investigate what latent worldviews provide the sociocultural constructs behind the litany layer. The language and conception play crucial roles in this stage because they do not simply reflect the world, but they constitute it, according to the post-structuralist premises of CLA. Although CLA is primarily a post-structuralist approach, in this layer of analysis, it utilizes discourse analysis as a theoretical framework as well as a methodology for social sciences and related studies in a broad sense. While different versions of discourse 
analysis (DA) meet various questions [28, 29], CLA mainly relies on critical discourse analysis (CDA), particularly the Foucauldian approach to CDA $[10,18]$.

"Struggle over meaning" is a crucial concept in this layer. Discourses as meaning orders articulate themselves around a focal node, which organizes some other nodes in turn to construct a cohesive and prevalent body of knowledge. However, there is no society in which just a single discourse can be identified practically. Although struggle over meaning is the dominant one, others quarrel to find more hegemonic positions. In addition, we should consider the fact that original discourses are usually limited and durable. As Foucault [30] indicates, mega-discourses are just two or three during a long period of time. Although there is a limited specific literature about the relationship between media and politics in early periods in which press media arrived in Iran as a new literary genre, and modernity converted into a political objective as a new body of knowledge, we can interpret some of the valuable inquiries [31, 32] demonstrating how the struggle for modernism crystallized the vital social and political transformations. As a result, we can track back to find a blueprint in which one of the most original discursive struggles has been triggered and continued for almost two centuries in the modern history of Iran. ${ }^{2}$

According to Sharifi [31], for instance, there are two basic pre-modern signifiers that constitute the official state discourse from the Shah Abbas Safavi era (15871629) until the 1906 Constitutional Revolution: Islam and security. Encountering Western modernity after 1870, new thoughts and opinions suggested some alternative signifiers in order to create several new imagined political discourses: law, development, people/democracy, and class/equality. After the mid-1850s, those who believed in Islamic politics were divaricated into two different groups: those traditionalists who rejected the West, due to its corruptive effects on Islam, and those modernists who advocated adopting the new Western values and concepts like constitution, citizenship, and civil law. Sharifi [31] concludes that we can trace all these contending signifiers in political texts after the 1900s, albeit with different sets of meaning.

Various genealogies of discourses, emerged from the early modern history of Iran in the nineteenth century until the present, have a common criterion for categorization: how to provoke a response to the west [32-34]. For instance, Hajarian [35] distinguishes three discourses based on which the relationship between "self" and "other" could be made: (1) "the deconstruction of tradition," in which tradition and its manifestations like Islam are considered to be the only factor that has caused Iranians to lag behind the civilization; therefore, they have to be abolished; (2) "the resurgence of tradition" in which the marginal elites, particularly leftists, strive to restore tradition to its focal position in social and political transformations; (3) "the reconstruction of tradition" in which several intellectuals in diverse camps make a widely decentralized effort to integrate the dynamic elements of tradition into modernism. Hajarian believes that the renewal begins after the Islamic Revolution of Iran in 1978-1979. However, the endeavor to reconciliation between tradition and modernity indicates implicitly that we should detect some types of struggle at first.

The struggle between tradition and modernity reached its culmination when the Iranian Revolution achieved final victory in 1978-1979. Under the umbrella of a charismatic cleric, Ayatollah Rouhollah Khomeini, the new political regime was established: the Islamic Republic of Iran. As this new title vividly indicates, the challenges between modernist and traditionalist discourses entered a new phase in which both discourses had some sort of political power in various governing bodies. It resulted in an ongoing gap between different administrative structures as well as political recruitments in recent years [36]. Those who were traditionalists before became radical modernists after. The essential gap historically occurred at the beginning of the new regime when Mehdi Bazargan, one of the most prominent modernist figures, was forced to resign from the head of Iran's interim government as the result of burdensome pressure from traditionalists who played a significant role in political decision-making, particularly after Khomeini supported the US Embassy takeover by one of the most radical Islamist groups, the Muslim Student Followers of the Imam's Line.

According to Soltani [32], modernists and traditionalists who were two wings of the revolution's victory and the supporters of Khomeini's leadership before the revolution split into two different camps advocating different focal nodes: Islamic versus Republican. Islamists who constitute the Islamic Republican Party (IRP) in early years utilized some discursive armaments such as "clergy," "supreme leadership," and "religious jurisprudence" in their controversies against modernists who tended to institutionalize some modern concepts such as "citizenry," "legislation," and "freedom". This discursive duality has lasted throughout the whole history of Iran's post-revolution era and crystallized thereafter in political controversies, particularly regarding presidential elections in which a pro-modernist candidate campaigned against a pro-traditionalist group of candidates [37-40].

The traditionalist discourse is being hyped by the mainstream media, as traditionalists have gained the upper hand in political power. They legally control not only the monopolized radio and television broadcasting 
system but also the necessary financial and legislative apparatus to propagate the traditional values in the public sphere. Dominated by pro-traditionalists, some executive organizations, which are not supposed to own a media platform, allocate a huge amount of resources to media practices. To understand how the traditionalist worldview is embedded in the mainstream media, it is enough to say, for instance, that according to the Deputy of Press and Information Affairs, affiliated to the Ministry of Culture and Islamic Guidance, ${ }^{3}$ there are 28 licensed legal Persian news agencies, of which at least 15 directly or indirectly belong to clerics and military organizations promoting traditionalism even through sport news services (like supporting the "hijab" worn by female athletes), in addition to the IRIB news department, which is the most powerful news agency due to the fact that it legally monopolizes the right of TV and radio broadcasting. Supported by different theocratic institutions, most of these organizations have their own platforms like newspapers, magazines, and periodicals. Despite the discursive diversity among different clerical or militant organizations, what they prescribe for the vast range of socio-cultural and political issues is always extracted from different versions of traditionalist discourse, whether the supreme leadership of a cleric plays a central role in a particular articulation or not.

Declining the dominant traditionalist discourse, the alternative media have always strived to promote modernist discourse. The alternative press media have conventionally played a vital role in the contemporary history of Iran; their highest peak coincides with the evolutionary periods that the rise against traditionalism becomes one of the essential axioms of social struggles to establish a more democratic political system. Dissenting journalists were always the leading figures of the constitutional movement from 1905 to 1911, nationalization of Iran's oil industry movement in 1951, and Iran's Revolution of 1979-1980. Regardless of some various aspects and objectives, they share a firm belief in the demolishment of the despotism as the main symbol of traditionalism. This notion is crystallized by the concept of "rule of law" during the constitutional age; "nationalization" by Mohammad Mossadegh, as an opposing prime minister who fought against the monarchy power; and "Republicanism" by national-religious factions supporting the Ayatollah Khomeini at the advent of the revolution. Iranian reformists then employed the power of alternative newspapers to rapidly expand a new version of modernist discourse, relied on the notation of citizenry as the focal node, articulating other signs like legislation, political development, civil society, freedom, and reforms. Although it was the dominant party from 1997 to 2005, the widespread closure of alternative newspapers in
2000 [40] was just a link of the long chain of events, indicating that Iran has a long run to be released from traditionalism.

Given that the Internet has been developing enormously all around the world, publishing becomes easier, and broadcasting emerges from the state's monopoly. The alternative media also has been growing in recent years. However, the pressure and constraint with which they are faced remain persistently as the discursive struggle which does not direct to a point of compromise or ultimate dominance. The rapid expansion of new ICT technologies provides a great opportunity to propagate the various modernist discourses by alternative media, including feminist approaches, liberal politics, environment advocacy perspectives, and leftist criticism. Considering the substantial modality of alternative media, including digitality, virtuality, interactivity, hypertextuality, networking, and simulating [41], the expansion of new ICT technologies facilitate alternative media practices, as different practitioners from different social strata could actively participate in the flow of communication and generate alternative contents through alternative channels like citizen journalism, telegram channels, advocacy group websites, and activist hidden forums. On the other hand, surveillance technologies are developed simultaneously by the state regime; hence, the traditional powerful institutions possess the more effective equipment to ban, block, filter, or slow down different parts of the Internet. It also enhances the ability of security organizations dominated by traditionalists to track dissident activities, keep records of their deficiency, and accuse them of dissident views and activities in their ordinary life. Consequently, not only the new ICT technologies create a new open virtual space to listen to more varying modernist voices through the alternative media but also they make it possible to suppress these voices by threatening modern individuals to disclose their personal information or prosecution of modernist advocacy groups based on media evidence.

\section{The metaphor: "A wise king educating an unworthy populace"}

To unfold the deepest layer of causes, we must go beyond the contemporary history of Iran's modernity to find an ultimate metaphor or myth behind the present situation and its social and cultural causes. As the history of media in the conventional sense goes back to the nineteenth century when the first periodicals aspiring to imitate Western newspapers were published [42], we should investigate another prevailing literary genre to identify the metaphor. In pre-modern Persian literature, a couple of prominent travelogues have been written for the illiterate populace to be trained, amused, and educated. In other words, these travelogues are some kinds 
of educational written forms with which the composer attempts to familiarize the readers with social and moral thoughts by the application of travel anecdotes, though they are considered to be some pieces of prose literature nowadays. The travelogues consist of the education of morality, social norms, wisdom, etc. with lots of information derived from travel anecdotes that the composers observed or heard from somebody else.

The notion of totalitarianism is also embedded broadly in the Iranians' ancient literature, as we can identify it in written pieces of Saadi of Shiraz, one of the most prominent composers of Iran in the medieval age. For instance, he tells many of his travel anecdotes in "Gulistan," chapter 7 , concerning the effects of education. However, he constantly emphasizes on the inability of ordinary people to become informed and knowledgeable. He quotes from a king that "he whose foundation is bad will not take instruction from the good; to educate unworthy persons is like throwing nuts on a cupola" [43]. The king actually rejects the possibility of pedagogy concurrent with the medieval notation of education, as his preference is "to extirpate the race and offspring of these people and to dig up their roots and foundations". Consequently, the good (Saadi himself, or generally "Darvishes") has to centralize his endeavor to educate the king by aphorism, as he names the first chapter of his book as "the manner of king".

The combined thematic content of travelogues provides a foundational metaphor for the relationship between media and politics, contrary to the hypothetically so-called concept of "the 4th pillar of democracy" in the Western history of media in the nineteenth century. At the advent of the modern era, Iranian intellectuals subsumed the notion of education into pedagogy in order to engender a new modern manner in the populace. Here, the role of a wise king is replaced with a couple of diverse modernist groups who avow their commitments, whether to educate all folks or to instruct the king on how to establish a more modern society in the early modern era, during the governance of Qajar Dynasty (1789-1925). The first Iranian periodicals were published during this period of time when the most prominent chancellor of Iran, Mirza-Taghi-Khan Farahani, known as Amir Kabir, founded an official newspaper in Iran, "Vaghaye Etefaghie," translated to "events," with a key slogan: "the kingly scramble of the majesty was busied with the education of peasants, merchants, tradespeople... as though he ordered the kingdom to publish this gazette..." [44]. Simultaneously, he established the first Iranian modern school, called "Dar al-Fanun," translated to "graduate school," to educate the students with new sciences including physics and mathematics. At the same time, the traditional schools ("Maktabkhaneh" translated to "school") were just teaching the conventional religious expertise and knowledge to train clerics. The basic establishment of "Dar al-Fanun," then, transformed into the first university of Iran, the "University of Tehran," by the founder of Pahlavi Dynasty (1925-1979). In the late nineteenth century, Iranian intellectuals had romantically pursued the project of raw modernization by pedagogy. They were operating in the aftermath of the Constitutional Revolution, including the failure of economic developments, as well as the solidification of order and security, and political conflicts caused by the decentralization of power.

This era is likely to be acknowledged as the era of "romanticizing education," given the fact that Iranian intellectuals not only advocated for a kind of sentimental individualism but also glorified the past splendidly. Firstly, the individualism (at least in the ontological level) was a prerequisite for any modern reformist who attempted to make more effective political and social constructions. These reformers sentimentally supposed that everybody naturally demands to be free as ever as the social structures allow them to remember the natural state of freedom. They believed the new media and modern schools must fulfill this prophecy by advocating the new social structures and opposing the obsolete orders. Secondly, supported by various adaptive perspectives, they attempted to provide a trialogue between Islam, pre-Islamic history, and modernity, while the outcome was usually apparent: modernity is an intrinsic quality that should see a revival in the ordinary people, brought about by pedagogy. Furthermore, the illiterate populace would absolutely embrace this reform, as they vividly perceived that any further delay could result in less progress and more despotism. Thus, they were unable to foresee how the new dictatorship of Pahlavi could simply emerge by the coup of 1921 .

In 1925, "Reza Khan," the first Pahlavi Shah of Iran, started enforcing a series of regulations, legislation, and coercive rules to modernize Iran's society. The coercive modernization, also called the authoritarian modernization [45], changed the previous anti-intellectual ideas about modernization and reform and transformed the process of bottom-up modernization by educating the ordinary people into a state-conducted project to coercively inject modernization and modern values into all social strata. During the whole Pahlavi era, Iran's state regime considered media platforms as the powerful instruments with which people can be educated with modern values and brought to adopt modern norms in their personal lives. At the same time, the government created a strict system for controlling media with licensing and censorship, to prevent critical and opposite media platforms from conducting realistic discussions about the authoritarian progress of modernization. When "Mohammad Reza Pahlavi," the second Pahlavi Shah of Iran, was appointed, the 
new government was again highly concentrated on the process of coercive modernization and did not tolerate any opposition against its politics regarding the enforcement of modern norms.

After the 1978-1979 Islamic Revolution, when a short period of media freedom provided with the new revolutionary atmosphere passed, the focal metaphor around the essential function of media as educational apparatus remained unchanged and the new regime just changed some marginal components of this fundamental metaphor. In his first public speech in Iran after 14 years living in exile, Ayatollah Khomeini stated that "Cinema is one of the civilization manifestation which has to serve to educate people". Along with the domination of Islamist discourses, the state regime legitimated the basic role of clerics or representatives to be in charge of educating people in all different aspects of social life, including the media practice, the pedagogical efforts in primary kindergartens, schools, universities, or other forms of unofficial education, like artistic activities and religious ceremonies. Furthermore, the state regime determined that the Islamic values and approaches must be the main core of any kind of education, conveyed by media contents generated by different governmental and ideological organizations. From the first months after the Islamic Revolution until now, the most crucial priority of the state regime concerning media has been focused on embedding Islamic values in media content in order to educate people in a top-down manner. Although the influence and reliability of media platforms have been doubted in different points, enormous budgets have been spent on different media genre, like costly movies, to serve the main focal metaphor, which is still about educating people and has never changed.

On the other hand, the alternative media in Iran is also organized to play the same role in educating people but with different content and approach. As the modernist discourses became the subaltern opponent after the Iranian Revolution, they attempted to use alternative media to fill the socio-political vacancy caused by the absence of any modernist response to any dilemma. In other words, the official state-owned and state-controlled media have been unable to realize that a civil society moving forward to the modern institutional orders cannot be easily persuaded by media content derived from traditional solutions. In this state of affairs, alternative media comply with an immense responsibility to diffuse the modern viewpoints in terms of what fallacies the public affirms as the result of mainstream media practices. This task is intrinsically perceived as an educational performance, even though it would be a concert, a foreign soap opera, a social media channel about a woman's right to refuse the compulsory veil, the sensational journalism, a TV series against the various minority stereotyping, or any other media forms and contents not regularly admitted by the governmental media, totalitarian legislation, and traditional discourses. Thus, the contradictory dialectic between tradition and modernity, at least in the media sphere, has been capable of maintaining for almost two centuries, since they both confess to a common metaphor to educate the public by media instead of pedagogy.

\section{Conclusions}

In this article, we attempt to investigate the multiple layers of causes that constitute the current relationship between media and politics in Iran. The interconnections of each layer have been established a long time ago and have been maintained rigorously. These interconnections are also beneficial in identifying which solutions might be suggested by for the problems in each layer. However, any given solution is not required to be simply practical, since different layers of analysis from apparent issues to the more deeply latent controversies or compromises take us into the more abstract notions that we cannot translate into a specific policy or agenda. Even though offering a solution is highly problematic, we point out our rational resolutions in the following table (Table 3), as it also summarizes our findings in each layer of analysis.

Through the analysis of the relationship between media and politics in Iran in four causal layers, we construct three possible scenarios for the future of media and politics in Iran. Inayatullah [3] argues that the possible scenarios for the future of the issue under the study can be constructed according to the results of each analysis layer. Litany-type scenarios are more instrumental, systematic-level scenarios are more policy oriented, and discourse scenarios intend to capture fundamental differences. Conversely, metaphor-type scenarios are equally discreet but articulate this difference through a poem, a story, an image, or some other right-brain method.

We construct three possible scenarios for the future relationship between media and politics in Iran

Table 3 Findings and solutions in each analysis layer

\begin{tabular}{|c|c|}
\hline Layers & Results and solutions \\
\hline Litany & $\begin{array}{l}\text { Mainstream media vs. alternative media-solution } \\
\text { is in increasing "freedom of speech" }\end{array}$ \\
\hline Systematic causes & $\begin{array}{l}\text { Semi-totalitarian regime vs. dissidents - solution is } \\
\text { that it has to be repulsed by the civil society, } \\
\text { completed by the market, and disarmed by ICT } \\
\text { technology advancement }\end{array}$ \\
\hline $\begin{array}{l}\text { Discourses/ } \\
\text { worldview }\end{array}$ & $\begin{array}{l}\text { Traditionalism vs. modernism-solution is in } \\
\text { the historical empowerment of modern } \\
\text { discourses to a compromise or supremacy }\end{array}$ \\
\hline Myth/metaphor & $\begin{array}{l}\text { Top-down education myth-solution is that the } \\
\text { prophecy of education should be thwarted by a } \\
\text { modernist responsibility to education vis-a-vis }\end{array}$ \\
\hline
\end{tabular}


according to the findings of the discourse/worldview layer. Through the discourse scenarios, we are capable of understanding the general and fundamental differences of various alternative scenarios in the long-term future. Moreover, we believe that discourse-based scenarios are relatively general and macro-level scenarios by which different audiences and interest groups can grasp the future's conditions of media and politics in Iran and conduct their policy plans through this understanding. While litany scenarios are more useful for managers and social cause scenarios are more beneficial for policy makers, discourse scenarios are constructed in a more academic manner and they are beneficial for grasping the long-term futures' alternatives.

Table 4 illustrates the nutshell of three possible scenarios for the future of media and politics in Iran:

The first scenario, "media struggle," is the scenario which shows the continuous struggle between the traditionalist discourse and the modernist discourse. In this scenario, Iran's state regime remains semi-totalitarian and it continues to dominate, control, and suppress the media sphere. While some private and commercial press and media continue to work and publish in the media struggle scenario, the state regime stays as the main actor which regulates and control independent media and supervises their content production to be in line with the regime's ideological and political purposes. The role of civil society as an actor in the relationship between media and politics in Iran remains fragile and insignificant, and it will not be able to make any considerable change in the media sphere. This scenario illustrates the limited and small changes and innovations in the telecommunication technological aspects in Iran. In other words, whether a revolutionary technological breakthrough emerges or not, the state regime will not allow new participatory media technologies to be imported and used in Iran with the help of suppressive policies and legislation.

The second scenario, "diverse media," is the scenario of modernist discourse predominance. It shows the emergence of more democratic dimensions in Iran's state regime. In this scenario, Iran's state regime starts to evolve from a semi-totalitarian regime to a more democratic political system in which freedom of speech and the diverse media sphere are considered legitimate and acceptable. Private and commercial media platform can work in a competition-based media market, and the state regime will play the role of facilitator and regulator in practical aspects, instead of owning and monopolizing media platforms. In this scenario, the new and transformative communication technologies emerge and become known and used among Iranian media consumers as well. In this sense, the level of state regime's control and surveillance in media sphere significantly decreases.

The third scenario, "surveillance media," is the scenario of the supremacy of the traditionalist discourse. In this alternative scenario, Iran's state regime grows to a more totalitarian system of government and increases its control over all aspects of the media sphere in Iran. The state-owned media become larger in number and more powerful with the help of state secured budgets, and private and independent media platform are not powerful and competitive enough to stay alive, effective, and agile. The civil society will be suppressed by the state regime and become more fragile and ineffective in the media sphere. The new technological breakthroughs will be used as surveillance tools in the state regime's hands to increase its control and dominance over the media sphere by using new ways of filtering and censorship.

There are several tiny and huge remarks supporting each of these explanatory scenarios, though none of them have any emancipatory notion to unfold a more desirable road map toward the preferred role of media in Iran's contemporary society with its colorful political communities. According to the agenda-setting theories of media effects, the media functions are more reliant on what to think of rather than what to act on. To think, one needs to be informed, but the education myth expects its audiences to behave. Herein, we can observe that the three scenarios described before are the alternative scenarios, but at the same time, they are homogeneous scenarios as well. They are alternatives, as they variously explain the most crucial discursive debates that shape the surface levels of the relationship between

Table 4 Possible scenarios for the future of media and politics in Iran

\begin{tabular}{|c|c|c|}
\hline Scenario (I): media struggle & Scenario (II): diverse media & Scenario (III): surveillance media \\
\hline Semi-totalitarian state remains & More democratic state emerges & State grows to more totalitarian regime \\
\hline $\begin{array}{l}\text { Oligopoly media market with state regulatory } \\
\text { dominance, controlling media content and } \\
\text { infrastructures }\end{array}$ & $\begin{array}{l}\text { More competitive media market with multi } \\
\text { stakeholders especially on infrastructures, } \\
\text { regulatory state without ownership }\end{array}$ & $\begin{array}{l}\text { Media market reduces to less state competitor from } \\
\text { different state sectors, no public or private sector } \\
\text { particularly in infrastructures }\end{array}$ \\
\hline Fragile civil society & More powerful civil society & Less powerful civil society \\
\hline $\begin{array}{l}\text { No evolutionary transformation in } \\
\text { media technology }\end{array}$ & $\begin{array}{l}\text { Some revolutionary transformation occurs, to } \\
\text { some extent free of state control or surveillance }\end{array}$ & $\begin{array}{l}\text { Surveillance technologies serve state and private } \\
\text { sectors to block or filter alternative voices }\end{array}$ \\
\hline Traditionalism vs. modernism & Modernism discourse predominance & Traditionalism discourse supremacy \\
\hline
\end{tabular}


media and politics in Iran, like policy making, media coverage characteristics, media ownership, political censorship, and official versus satellite TV channels' competition. However, these scenarios are homogeneous in a way, because none of these explained significant disparities between modernist and traditionalist agenda violates the pervasive reality that there is one single and common myth behind both the competing discourses. None of the traditionalism and modernism discourses represents itself to be singled out for some unique superiorities; nevertheless, they implicitly claim that people should learn to adhere to their universal values due to their usefulness, legitimacy, novelty, antiquity, etc., whether the instrumental device to accomplish this task is pedagogy or media.

In the emancipatory and desirable scenario, we are seeking a future in which the media play their role as the 4th pillar of democracy, where they just serve to inform rather than to educate. In this alternative future, the political interest groups and the market or the state regime will be limited to echoing their voice throughout the public through their labeled and known media campaigns, while the independent and public media reflect the voice of the voiceless and deliver the marginalized groups' demands to the powerful politicians and firms. In other words, the futures scenarios that we previously constructed based on the results of the discourse level elucidate the explanatory alternative scenarios which possess a greater possibility of becoming the reality. However, there is no limitation for a critical approach to consider a wider vision of the future in which the controversy between traditionalism and modernism in Iran ends, and instead, a balanced synthesis of tradition and modernity provides the prospect of a new postmodern relationship between media and politics in Iran. Despite the possibility of such a future vision and aside from the presence of signs and evidence for the end of traditionalism-modernism conflict, a futures scenario in which the relationship between media and politics become redefined and reframed through a new discourse and a new power balance is the most desirable alternative for the future of media and politics in Iran.

We believe that shaping an alternative emancipatory scenario for the future of media politics in Iran requires going beyond the boundaries of the modernist and traditionalist forces which define the crucial social contradictories in the systemic level and crystalize media hostilities in the litany level. In other words, we believe that uncovering the effects and influences of these discourses on the relationship between media and politics and discussing the alternatives are the essential responsibility of any critical study as our own normative stand. What we have done in this paper is to highlight how both the modernist and traditionalist discourses competing throughout the contemporary Iranian's history articulate a very peculiar relationship between media and education. Having a critical approach, we aimed to deconstruct the myth of education behind the relationship between media and politics, in hope of constructing alternative desirable futures in which media play their actual role as the fourth pillar of democracy.

\section{Endnotes}

${ }^{1}$ In addition to executive branches, legislative and judiciary bodies have their own media. There are also several media organizations like IRIB and Jam-e-Jam newspaper that are directly controlled by the supreme leader, while other institutions, legally under the supervision of the supreme leader, like military forces and economic foundations, play a significant role in administering some media platforms financially or even editorially.

${ }^{2}$ In this section, we mainly rely on several scientific sources that track back Iran's historical transformation after the nineteenth century with the concrete fact of Western modernity's entrance into undeveloped traditional parts of the world like the Middle East, Latin America, or China. As there is a rich literature about this issue with various scopes and focuses about Iran, quite a few inquiries directly employ DA and almost no record can be found similar to our purpose. Consequently, we decide to reread and process again the pieces mentioned about the relationship between media and politics in a specific historical period and broadly classified political discourses in a wide period of time on one hand and extract a coherent and continuous narrative about the historical transformation of the traditionalist struggle against modernity on the other hand. Although this kind of meta-analysis of secondary sources has its own flaw, it is the only practical and reliable way to verify our arguments in this paper, as our ambitious gigantic research project to DA of the media documents like the newspaper's editorial columns after 1857 is being conducted to understand which micro discourses could be identified under the larger ones.

${ }^{3}$ The information here is extracted by authors according to raw data released by the deputy of press and information affairs on November 25, 2017. Follow this link to access the Excel raw data file: https:// press.farhang.gov.ir/fa/kb/96

\section{Authors' contributions}

ST drafted the manuscript, carried out the the methodological studies, collected the data and material for the litany level and the social cause analysis, and participated in the process of scenario building and developing the discussions and conclusions. HT developed the design of the study, carried out the studies and analysis in the discours and the metaphore levels, and participated in the process of scenario building and developing 
the discussions and conclusions. Both authors read and approved the final manuscript.

\section{Competing interest}

The authors declare that they have no competing interests.

\section{Publisher's Note}

Springer Nature remains neutral with regard to jurisdictional claims in published maps and institutional affiliations.

\section{Author details}

${ }^{1}$ Helsinki University, Helsinki, Finland. ${ }^{2}$ Culture, Art and Communication Research Ins., Tehran, Iran.

\section{Received: 10 August 2017 Accepted: 23 May 2018}

\section{Published online: 14 June 2018}

\section{References}

1. Mohsenian Rad M (2006) Iran in four communication galaxies. Soroush Press, Tehran

2. Abrahamian E (1979) The causes of the constitutional revolution in Iran. Intl J Middle East Studies 10(3):412-414

3. Inayatullah S (2004) The causal layered analysis reader. Tamkang University Press, Tamsui

4. Ramos JM (2003) From critique to cultural recovery: critical futures studies and causal layered analysis. Australian Foresight Institute Swinbourne University, Melbourne

5. Inayatullah S (2008) Six pillars: futures thinking for transforming. Foresight 10(1):4-21

6. Lederwasch ea (2001) A vision for mining and minerals: applying causal layered analysis and art. J Futures Studies 15(4):25-40

7. Shevellar $L$ (2011) "We have to go back to stories": causal layered analysis and the community development gateaux. J Community Development 42(1):3-15

8. Bishop BJ, Dzidic PL (2014) Dealing with wicked problems: conducting a causal layered analysis of complex social psychological issues. Am J Community Psychol 53(1-2):13-24

9. Hiltunen E (2013) Foresight and innovation. Palgrave Macmillan, London

10. Inayatullah S (1990) Deconstructing and reconstructing the future: predictive, cultural and critical epistemologies. Futures 22(2):115-141 https://www.journals.elsevier.com/futures

11. Iran's constitution (1979) http://rc.majlis.ir/fa/content/iran_constitution. Accessed 15 Nov 1979

12. The statute of Islamic radio and television broadcasting (1983) http://rc. majlis.ir/fa/law/show/90402?keyword=\%D8\%B5\%D8\%AF\%D8\%A7 +\%D8\%B3\%DB\%8C\%D9\%85\%D8\%A7. Accessed 17 Nov 1983

13. ASP regulations (2008) http://www.mimt.gov.ir/index.php?module= cdk\&func $=$ loadmodule\&system $=c d k \&$ sismodule=user/content_view php\&cnt_id=103281\&ctp_id=23\&id=18570\&sisOp=view. Accessed 29 Jan 2009

14. Aryan S, Aryan H, Halderman JA (2013) Internet censorship in Iran: a first look. Washington: FOC

15. Iran's press law (1985) http://press.farhang.gov.ir/fa/rules/laws2. Accessed 6 Mar 1986

16. Djankov S, McLeish C, Nenova T, Shleifer A (2003) Who owns the media? Law Econ 46:341-381

17. Iran's underground newspaper called Khiaboon (2010). http://ireport.cnn com/docs/DOC-395440

18. Inayatullah S (1998) Causal layered analysis: poststructuralism as method. Futures 30(8):815-829

19. Articles of Association of Telecommunications Infrastructure Company (TIC) (2013). https://old.tic.ir/Content/media/image/2011/11/10326 orig.pdf

20. The law for administration of radio and television broadcasting in Iran (1980) http://rc.majlis.ir/fa/law/show/90104?keyword= \%D8\%B5\%D8\%AF\%D8\%A7+\%D8\%B3\%DB\%8C\%D9\%85\%D8\%A7

21. Boroumand L, Boroumand R (2000) Illusion and reality of civil society in Iran: an ideological debate. Soc Res 67(2):303-344

22. Khiabany $\mathrm{G}$ (2007) The politics of broadcasting in Iran: continuity and change, expansion and control, Television and public policy: change and continuity in an era of global liberalization, pp 285-302
23. Khiabany G (2007) Iranian media: the paradox of modernity. Soc Semiot 17(4):479-501

24. Arjomand SA (2000) Civil society and the rule of law in the constitutional politics of Iran under Khatami. Soc Res 67(2):283-301

25. Khiabany G, Sreberny A (2001) The Iranian press and the continuing struggle over civil society 1998-2000. Gazette (Leiden, Netherlands) 63(2-3): 203-223

26. Samii AW (2001) Sisyphus' newsstand: the Iranian press under Khatami. Middle East 5(3):1-11

27. Barraclough S (2001) Satellite television in Iran: prohibition, imitation and reform. Middle Eastern Studies 37(3):25-48

28. Jørgensen MW, Phillips LJ (2002) Discourse analysis as theory and method. Sage, pp 8-23

29. Gee JP (2014) An introduction to discourse analysis: theory and method. Routledge, pp 8-10

30. Foucault M (1989) The order of things: an archaeology of the human sciences. Routledge, London

31. Sharifi M (2008) Imagining Iran: contending political discourses in modern Iran. Gainesville: University of Florida

32. Soltani A (2005) Power, discourse, and language. Ney Publication, Tehran

33. Ghaninezhad M (2015) Modernization and development in contemporary Iran. Tehran: Markaz Publication

34. Tajik M (2008) The discourse analysis of the ninth presidential election in Iran.Half-Yearly Persian. Lang Lit 16(61):83-126

35. Hajarian S (1997) The typology of intellectual streams in contemporary Iran. Res Lett 7(2):23-40

36. Bashiriyeh H (2011) The state and revolution in Iran (vol. 27). Routledge, London

37. Tajik M, Roozkhosh M (2008) Consideration of the 9th period of Iranian presidential election. Lit Hum Sci Faculty J 16:83-126

38. Jahangiri J, Fattahi S (2011) The discourse analysis of "Mahmoud Ahmadi Nejad". In: 10th presidential election. Iran's social studies magazine 5(3), pp 23-47

39. Mirzaei M, Rabani-e-Khorasgani M (2016) The analysis of contrast between principlism and reformism discourses in the 10th presidential election in Iran. Appl Sociol 26(4):45-68

40. Nariman S, Azizi R (2016) The multi-layer model of analysis of 11 th presidential elections. Theor Political Res 19:29-65

41. Lister M (2009) New media: a critical introduction. Taylor \& Francis, pp 13-44

42. Bashir $\mathrm{H}$ (2000) The Iranian press and modernization under the Qajars, Doctoral dissertation, Mass Communication at the university of Leicester, pp 106-156

43. Gladwin F, Ross J (1865) The gulistan: or rose garden. Ticknor and Fields, Tehran

44. The editorial (1850) Vaghaye Etefaghie 1(1):

45. Atabaki T, Zurcher EJ (2004) Men of order: authoritarian modernisation in Turkey and Iran: 1918-1942. London: IB Tauris

\section{Submit your manuscript to a SpringerOpen ${ }^{\circ}$ journal and benefit from:}

- Convenient online submission

Rigorous peer review

Open access: articles freely available online

- High visibility within the field

Retaining the copyright to your article

Submit your next manuscript at $>$ springeropen.com 